\title{
东海底栖有孔虫区系的初步分析*
}

郑执中郑守仪 傅钊先

(中国科学院海洋研究所)

有孔虫的生态研究和区系分析, 不仅有助于阐明现代海洋环境, 且对推断或重建古海洋环 境、研究古海洋学乃至对石油勘探的实际应用等,均具重要意义.

关于东海有孔虫区系, Polski (1959) 曾作过粗略研究 ${ }^{[1]}$, 笔者 (1963) 也曾初步探讨过黄、 东海及邻近水域浮游有孔虫的地理区划 ${ }^{[2]}$ 。但这都没有对东海底栖有孔虫区系进行较系统的 分析研究。

我们根据我所历年来采自东海 $26^{\circ} 28^{\prime}-33^{\circ} 00^{\prime} \mathrm{N} 、 121^{\circ} 00^{\prime}-128^{\circ} 52^{\prime} \mathrm{E}$, 水深从 8 米至 2,150 米范围内的 202 个测站的表层沉积物样品 (每一测站取干样 50 克经孔径 0.15 毫米分 样篮篮 洗后，烘干、浮选)，进行了有孔虫定量分析.

经初步鉴定,东海调查区计有底栖有孔虫 700 多种, 种类虽多,但优势种十分显著, 仅数量 最多的前 10 个种即占全调查区底栖有孔虫总个数的 $57 \%$ 左右. 种类组成甚为复杂, 少数暖 温带种自黄海分布至东海, 有的种类可能与日本及朝鲜有孔虫区系有一定联系, 多数则属印 度-西太平洋区系的种. 总观其深度分布, 约有 70\% 的种类分布于水深 50-200 米的区域, $10 \%$ 左右分布于 $<50$ 米的近岸区, $20 \%$ 左右分布于 $>200$ 米的深水区.

底栖有孔虫总数和种数总的分布趋势是, 河口区稀少, 自内陆架向中、外陆架迅速增多, 越 过陆架外缘至上深海区、深海区即显著减少. 水深 50-100 米左右的中、外陆架数量最多, 一 般为 5 千至 1 万个 $/ 50$ 克干样, 若干测站多达数万个 $/ 50$ 克干样; 种数向外陆架与陆架外缘继 续递增到 90-100 种。底栖有孔虫三种壳壁类型的数量百分比, 以钻质有孔型最高, 砂质胶结 型次之,钻质无孔型最低。

调查区的 $P / B$ 值 (浮游有孔虫总数/底栖有孔虫总数) 以及底栖有孔虫的复合分异度 $H(S)$ 值、多变度 $V$ 值和优势度 $d m_{5}$ 值 (每测站前列五个优势种的百分比总和) 的分布规律, 可 以清楚地反映出不同水系的分布格局及其相互制约的程度. 总的看来, 在黑潮主流 区 $P / B$ 值、 $H(S)$ 值和 $V$ 值最高, $d m_{5}$ 值最低; 黑潮流系扩展影响区, $P / B$ 值、 $H(S)$ 值和 $V$ 值较高, $d m_{5}$ 值较低; 黑潮流系与大陆沿岸水、南下黄海冷水的交汇区, $P / B$ 值、 $H(S)$ 值和 $V$ 值均较低, $d m_{5}$ 值则较高; 而在大陆沿岸水和南下黄海冷水影响显著的区域, $P / B$ 值、 $H(S)$ 值和 $V$ 值甚 低, $d m_{5}$ 值则甚高.

在一个生态作用较为均一的环境中, 就有可能形成独特的生物区系相. 普遍出现而且出 现率较高的优势种属, 常具有指示环境特征的作用. 因此, 动物区系的自然划分, 首先应该依 据优势种属的出现率和区系组成成分与主要环境因子之间的关系来确定.

本文 1979 年1月 25 日收到.

* 中国科学院海洋研究所调查研究报告第 467 号. 





我们主要依据各测站底栖有孔虫前五位优势种出现率的排列顺序及其生态特征, 并参考 $P / B$ 值、 $H(S)$ 值、 $V$ 值和 $d m_{5}$ 值等参数的分布规律, 初步将东海调查区底栖有孔虫划分为八 个区系七个亚区 (表 1、图 1).

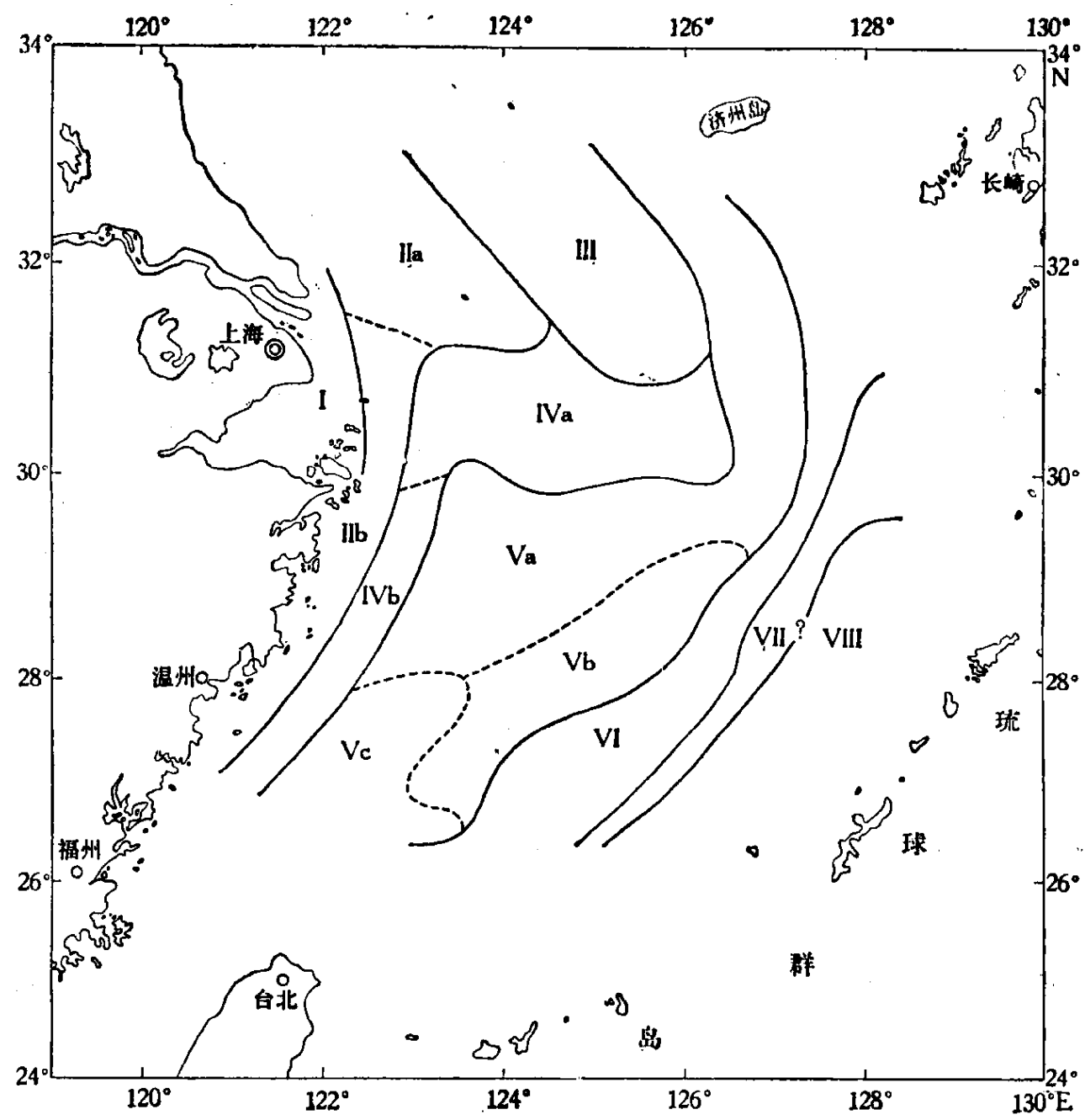

图 1 东海底栖有孔虫区系

区系 I 河口-滨岸区系, 局限于杭州湾、长江口, 以半咸水性或广盐性种类为主.

区系 II 内陆架区系,位于江、浙近岸,包括长江口大沙滩,浅水种为主要成分. 大致以 长江口和大沙滩南沿为界，分为两亚区: IIa 亚区受江苏沿岸流控制，与苏北沿岸区系相连; IIb 亚区混杂少量暖水性种类.

区系 III 中陆架区系, 位于黄、东海交界, 受黄海冷水显著影响, 与黄海南部区系密切 联系. 区系组成较为单纯, Pseudorotalia gaimardii (d'Orbigny) 占绝对优势 $(>50 \%)$.

区系 IV 亦属中陆架区系, 位于东海陆架中部, 是南下黄海冷水、江苏沿岸水与北上暖 流水的混合区. 区系组成呈现混合过渡特征,含有暖温带种和热带、亚热带种. 分两亚区: IVa 亚区含较多暖温带种; IVb 亚区偏南,则混和较多暖水性种.

区系 V 外陆架区系, 大致以 $30^{\circ} \mathrm{N}$ 纬度线与区系 $\mathrm{IVa}$ 为界，处于黑潮流系直接影响 区. 分为三亚区: $\mathrm{Va}$ 区以暖水种为主, 仍含有一定数量与黄海共有种, 显示黄海冷水势力尚 可影响到本亚区,另一方面,本亚区向济州岛西南方向延伸部分,显示黄海暖流的趋向.Vb 亚 区已迫近黑潮主流区,以典型暖水种为主体. $\mathrm{V} c$ 亚区处于台湾暖流区, 亦以典型暖水种为主, 
可能与台湾海峡北面海域的区系紧密相连.

区系 VI 陆架外缘区系，正处黑潮主流控制区，以典型热带种为主体，含有深水种成 分. 种、属分异度大.

区系 VII 陆坡(上深海)区系,仍在黑潮主流控制区,区系组成以暖水种为主,因水深增 大,深水种成分增加. 目前从陆坡至海槽之间的测站尚少, 资料不足, 对这一区系的深度分布 下界尚难明确划分. 推测这一下界有可能接近于黑潮影响所及的深度界线.

区系 VIII 海槽区系, 以典型深水种为主体, 并含有若干与终年为冷水团所盘据的北 黄海中央海盆共有类型. 这显示这两个隔离很远的海盆, 可能在某些环境条件有相近似之 处.

深层水团或海流直接作用于海底，对底栖生物起着一定的生态效用。黑潮分支与台湾暖 流自底层楔入东海中部, 造成该区终年相对稳定的外海海洋环境, 不少热带或亚热带底栖有孔 虫得以在当地环境中生长繁殖, 并非自外海搬运而来的. 不同水团之间的变化是逐渐的, 这反 映在相邻区系之间也是逐渐过渡的，区系界线实际上是表示过渡带的平均位置. 不同水团或 海流的交汇锋面，常成为区系之间的自然界线。上述底栖有孔虫区系的分布格局，清楚地反 映出东海几个主要流系 (大陆沿岸流、黄海冷水、黑潮流系、台湾暖流等) 的平均分布趋 向.

\title{
考文献
}

[1] Polski, W., Jour. Pal., 33 (1959), 4: 569-587.

[2]郑执中、郑守仪,海洋与湖沼, 5 (1963), 3: 207-214.

\section{PRELIMINARY FAUNAL ANALYSIS OF THE BENTHIC FORAMINIFERA OF THE EAST CHINA SEA}

\author{
Zheng Zhi-zhong (Cheng Tsi-chung, 郑执中), \\ Zheng Shou-yi (郑守仪) and Fu Zhao-xian (傅到先)
}

\begin{abstract}
A quantitative analysis is made of the benthic foraminiferal content of 202 East China Sea surface sediment samples collected from the coastal regions to the Okinawa Trough. More than 700 species are preliminarily identified. Based on specific and nonspecific faunal characteristics, 8 assemblages and 7 sub-assemblages which are useful as indicators of different kinds of environment are recognized.
\end{abstract}

